\title{
Report of a Zoanthus Zone from the Cabo Verde Islands (Central Eastern Atlantic)
}

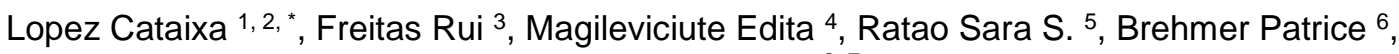 \\ Reimer James D. 2, 7
}

${ }^{1}$ ULL, Fac Ciencias, Dept Biol Anim Edafol \& Geol, Ave Astrofis Francisco Sanchez S-N, San Cristobal De La Lagu 38206, Spain.

2 Univ Ryukyus, Fac Sci, Dept Biol Chem \& Marine Sci, Mol Invertebrate Systemat \& Ecol Lab, 1 Senbaru, Nishihara, Okinawa 9030213, Japan.

3 Univ Cabo Verde Uni CV, Fac Engn \& Ciencias Mar, Mindelo 163, CP, Cape Verde.

${ }^{4}$ ECOCV, Assoc Cabo Verdiana Ecoturismo, Santiago Isl 7600, Cape Verde.

${ }^{5}$ FMB, Cidade Do Porto Ingles 6110, Maio Island, Cape Verde.

${ }^{6}$ CRODT Pole ISRA Hann, Inst Rech Dev IRD France, UMR 195 Lemar, Dakar, Senegal.

7 Univ Ryukyus, Trop Biosphere Res Ctr, 1 Senbaru, Nishihara, Okinawa 9030213, Japan.

* Corresponding author : Cataixa Lopez, email address : clopezba@ull.edu.es

ruifreitas@docente.unicv.edu.cv ; edita.magileviciute@icloud.com ; ratao.sara@gmail.com ; patrice.brehmer@ird.fr ; jreimer@sci.u-ryukyu.ac.jp

\begin{abstract}
:
Zoanthus is a genus of colonial cnidarians very common in shallow subtropical and tropical rocky and coral reef ecosystems around the world. Some species, such as Zoanthus solanderi and Z. sociatus, can coexist and cover extensive areas in the subtidal zone of some areas in the Caribbean. We report on a Zoanthus zone' in Western Africa in a bay in the north of Maio Island in the Cabo Verde Archipelago, discovered in October 2014. Molecular analyses showed that the Maio Island carpet is formed by Z. sociatus and Z. solanderi. Similar aggregations have been reported from the other side of the Atlantic Ocean in the Caribbean. This work demonstrates the presence of the Zoanthus zone' in the Central East Atlantic and adds two new records of Zoanthus species in the Cabo Verde Islands.
\end{abstract}

Keywords: Marine biodiversity, Maio Island, Molecular analyses, West Africa, Zoanthus sociatus, Zoanthus solanderi 


\section{INTRODUCTION}

Zoantharians (Anthozoa: Hexacorallia) are an order of colonial cnidarians with species found in most marine environments from temperate to tropical areas and from the intertidal zone to the deep sea (Ryland and Lancaster 2003). In particular, the zooxanthellate genera Zoanthus and Palythoa are common in subtropical and tropical shallow rocky and coral reef ecosystems (Karlson et al. 1981; Irei et al. 2011) usually as discrete colonies formed by hundreds of polyps. However, some zoanthids species, such as $P$. caribaeorum, are frequently found covering large areas in the subtidal zones (Sebens 1982; Acosta 2001). In 1981 Karlson and collaborators discovered, on the north coast of Jamaica, the unique place where it is known that local populations of Zoanthus solanderi (LeSueur 1818 sensu Karlson 1980) and Z. sociatus (Ellis 1768) can cover a huge portion of the intertidal zone. The area occupied by these two species is so huge that this portion of the intertidal has been called the 'Zoanthus zone' (Karlson et al. 1981). In October 2014 a huge Zoanthus aggregation was accidentally discovered in Porto Cais Bay, one of the northernmost and sheltered areas of Maio Island, Cabo Verde. This bay is characterized by being a flat area of warm shallow waters affected by semi-diurnal microtidal low current regimes with relatively low transparency due to terrigenous material accumulation in the water column from leaching. Porto Cais Bay is included in the protected Nature Park of the North of Maio Island (PNNM). This Nature Park is part of a network of protected areas implemented in 2003 with a significant expansion of marine area and final boundaries including a marine area were set in 2014 (Anonymous, 2014). .

It is known that several coral species, including zoanthids (Pax and Müller 1956; Reimer et al. 2010), have an amphi-atlantic distribution (Nunes et al. 2011), however, Z. solanderi and $Z$. sociatus have never been found in Cabo Verde. In fact, only one species of Zoanthus has been reported from the Archipelago until now, Z. aff. pulchellus (Duchassaing and Michelotti 1864) (Reimer et al. 2010), and there is no record that this species has the ability to grow disproportionately. On the other hand, Z. aff. pulchellus is characterized by having polyps partially 
or completely embedded in a well-developed coenenchyme (Reimer et al. 2010) and the species located in Maio had liberate polyps.

In this study we report on this large aggregation showing that the Zoanthus zone in Jamaica is not an isolated event and some zoanthids species can overspread large areas. Moreover, we utilize both morphological and molecular analyses in order to identify the species of Zoanthus. Our aim is to demonstrate if the ability of cover huge areas is characteristic of Z. solanderi and Z. sociatus and therefore, we registered two new records of Zoanthus species in Cabo Verde, or if on the contrary, this massive grow is common in other Zoantharian species.

\section{MATERIAL AND METHODS}

\section{Study site, specimen collection and initial in situ identification}

This study was carried out around Maio Island, situated on the largest insular shelf in Cabo Verde Archipelago. The Zoanthus aggregation was discovered in Porto Cais Bay $\left(15^{\circ} 18.95^{\prime} \mathrm{N}\right.$, $23^{\circ} 11.06^{\prime} \mathrm{W}$ ) (Figure 1) at around $1.5 \mathrm{~m}$ depth in October 2014. For an accurate outer boundary of the Zoanthus aggregation a thorough survey was carried out in October 2016 by snorkeling around the outer edge while obtaining a total of 31 geo-referenced points (in UTM WGS 84) taken with a waterproof GPS receiver. The QGIS (2016) open source software was used to estimate the area as a polygon of the 'Zoanthus zone' in Porto Cais Bay, Maio Island based on geo-referenced points.

Species were initially identified as Zoanthus spp. due to the lack of sandy or muddy encrustations in the body wall. However, the specimens had polyps well clear and free of the coenenchyme, indicating that the component species of the aggregation were not Z. aff. pulchellus (Figure 2). Underwater digital images taken in situ were used for subsequent gross morphological analyses including polyp shape, numbers of tentacles, coenenchyme development, and colour $(\mathrm{n}=$ 30 polyps analyzed). While there are historical records of zoantharians in the East Atlantic (e.g., Van der Land 1993; Morri et al. 2000), many species of Zoanthus remain hard to identify in the 
field due to high levels of intraspecific variation resulting from phenotypic plasticity of polyp shapes, colours, sizes, and oral disk colours (Reimer et al. 2004; Ong et al. 2013). Therefore, we identified specimens from Maio Island by utilizing a DNA barcoding approach.

\section{DNA extraction and PCR amplification}

For molecular analyses, polyps from both Zoanthus morphotypes ( $\mathrm{n}=$ four colonies) were collected (Figure 2). DNA was extracted from 50mg of body tissue following the manufacturer's protocol of a DNeasy Blood \& Tissue Kit (Qiagen. Tokyo). The nuclear internal transcribed spacer region of ribosomal DNA (ITS-rDNA) was amplified by polymerase chain reaction (PCR) using primers designed by Swain (2009). Mitochondrial cytochrome oxidase subunit 1 (COI) was

amplified using newly designed zoantharian-specific primers (COIZPF 5'GAACTATGTTGGGGGACGAC 3', COIZPR 5'-GGCGGGGTCAAAGAAAGTAG - 3') based on a sequence obtained with the general COI primers of Folmer et al. (1994). Products obtained by PCR were checked by $1 \%$ agarose gel electrophoresis and positive reactions sequenced in both directions at Fasmac (Kanagawa, Japan).

\section{Phylogenetic analyses}

DNA sequences generated in this study were aligned with previously reported sequences in GenBank (Altschul et al. 1990) using ClustalW (Thompson et al. 1994) implemented in MEGA v.7 (Kumar, Stecher and Tamura 2015). The alignments were cleaned by eye and ambiguous sites were removed prior to analyses. A suitable outgroup to each alignment was added to the phylogenetic analyses.

The best-fitting DNA model of nucleotide substitution was determined for each data set according to the Bayesian Information Criterion (Schwarz 1978) in Jmodeltest (Darriba et al. 2012). Phylogenetic trees were inferred using MrBayes (Huelsenbeck and Ronquist 2001) and RAxML 
(Ott et al. 2007) software through the Mobyle SNAP Workbench (Monacell and Carbone 2014). Posterior distributions of trees and parameters were estimated using Markov Chain Monte Carlo (MCMCs) for 5000000 generations sampled every 100 generations. The consensus trees were visualized with Fig.Tree v1.4.2 software (Rambaut 2009).

\section{RESULTS}

The zoantharian area was approximately estimated at 4 hectares with a perimeter of approximately 800 meters (Figure 1). The underwater video transect of the carpet (video available at https://youtu.be/CduwshatD60) revealed that below the colonies, the benthos was dominated by typical local stony coral species (i.e., Siderastrea radians, Porites spp., Millepora alcicornis) attached to isolated pavements (Moses et al. 2003).

We observed two morphotypes within the 'Zoanthus zone'. All Zoanthus polyps were 'liberae', i.e., well free and clear of coenenchyme (Pax 1910), connected by a poorly developed coenenchyme. This grow form differ to the Zoanthus species already registered in Cabo Verde, $Z$. aff. pulchellus, whose polyps are embedded in a well-developed coenenchyme (Reimer et al. 2010). The number of tentacles varied from 36 to 58 and colour patterns of an oral disk varied from green and fluorescent green to yellow. According to previous studies these characteristics are similar to both Z. sociatus and Z. solanderi found in the Caribbean Sea (Sebens 1982; Reimer et al. 2012).

The two morphotypes could be clearly distinguished by the sizes of the polyps. One morphotype had polyps with an average oral disc diameter of $3.2 \pm 0.6 \mathrm{~mm}(\mathrm{n}=6$ polyps examined), while the other morphotype was smaller $2.64 \pm 0.53 \mathrm{~mm}(\mathrm{n}=11$ polyps $)$. The larger morphotype had white striped vertical markings on the body walls of polyps, similar to as previously reported for Z. solanderi (Karlson 1980), and the oral disk varied in colour (green, brown, grey) with white dots present. The smaller morphotype matched well with Z. sociatus, as this species has many colour morphotypes. We observed a grey oral disk with yellow or green 
fluorescent in the middle (Figure 2). The sizes of each morphotype also fit well within values previously reported for each species.

Both ITS-rDNA and COI sequences from the specimens each showed two different genotypes, one for each morphotype. ITS-rDNA sequences from specimens morphologically identified as Z. solanderi (ID 91, 92 and 93 on the phylogenetic tree) were identical to previously reported sequences of Z. gigantus from Japan (DQ442412, DQ442465), the Pacific sister species of Atlantic Z. solanderi (Reimer et al. 2012). COI sequences from these specimens were also similarly identical to Z. gigantus from Japan (AB252675, AB252673). Based on combined results, these three specimens were identified as Z. solanderi. Both ITS-rDNA and COI sequences from the other morphotype (specimen ID94 on the phylogenetic tree) grouped with previously reported Z. sociatus sequences (JX119131, JX119133, KT454373, KT454372) from Florida and Brazil, and thus this specimen was identified as Z. sociatus.

Similar Zoanthus aggregations were also subsequently observed in two more locations on more northerly Boavista Island in Cabo Verde (i.e., Derrubado and Gatas Bays; Carlos ML Afonso Pers. Comm.). However, field surveys of other sheltered bays off the western coast of Maio Island (Ponta Rica, Calhetinha, and two bays in Pau Seco) in October 2016 revealed no Zoanthus spp. (triangular arrows in Figure 1).

\section{DISCUSSION}

Our results showed that the Zoanthus aggregation in Porto Cais Bay, Maio Island was composed of two species: Z. sociatus and Z. solanderi. It has been previously observed that these two species can reach high densities (Karlson 1981) while covering extensive areas of reef flats in the Caribbean Sea, and such areas have been called the 'Zoanthus zone' (Sebens 1977). This work reports for the first time the presence of such a 'Zoanthus zone' in the central Eastern Atlantic. While it is not known in this 'Zoanthus zone' is a recent occurrence or not, it is known that 
Zoanthus spp. can asexually reproduce (Burnett et al. 1995), and that they can expand their benthic coverage rapidly after disturbances (Wee et al. 2017). Polyclonal Zoanthus aggregations are theorized to be beneficial to success of sexual reproduction (Karlson 1988). Although the Pau Seco area is similar to Porto Cais Bay, both Pau Seco bays are more hydrodynamic (current and wind intensities) with steeper slopes and a more complex topography of the substrata (sand and rubble) in comparison to the 'Zoanthus zone' location found at Porto Cais Bay; these facts may explain the absence of Zoanthus spp. in Pau Seco. Detailed exploration around the Cabo Verde Archipelago and neighbouring islands is needed to confirm if the Zoanthus zone is a common occurrence in this region or a relatively unique ecosystem. However, until now, no such zone has been reported in any of the Cabo Verde Islands or along the West African coasts, and thus it is likely that this is either a relatively rarely occurring ecosystem and/or has appeared relatively recently in this part of the Atlantic Ocean. Long-term monitoring of the site at Porto Cais Bay is needed to understand if the 'Zoanthus zone' is expanding or not, and to elucidate the long-term dynamics of this phenomenon. Future investigations should try to elucidate if such 'Zoanthus zones' are native to Cabo Verde or rather recently arrived due to an anthropogenic effect (e.g., invasive species, phase shift (Cruz et al. 2015)).

\section{ACKNOWLEDGEMENTS}

We thank the University of Cabo Verde for support in the prospecting survey and Nivaldo Ramos (FMB) for local assistance and field equipment. We are thankful the FMB local NGO for providing the opportunity to undertake this study. We are indebted to Mariano Hernández for his kindly help in primers designs and Carlos M. L. Afonso (UAlg, CCMar) for shared information on Zoanthus colonies. The Agencia Canaria de Investigación (ACIISI) and Fondo Social Europeo supported CL's internship in Okinawa, Japan where analyses were carried out. The senior author was 
supported by JSPS Kiban B grant entitled "Global evolution of Brachycnemina and their Symbiodinium".

FINANCIAL SUPPORT

This research received no specific grant from any funding agency, commercial or not-for- profit sectors.

\section{CONFLICT OF INTEREST}

On behalf of all authors, the corresponding author states that there is no conflict of interest. 


\section{References}

Acosta A (2001) Disease in Zoanthids: dynamics in space and time. Hydrobiol 460: 113130

Altschul SF, Gish W, Miller W, Myers EW, Lipman DJ (1990) Basic local alignment search tool. J Mol Bioly 215: 403-410

Anonymous (2014) Boletim Oficial da republica de Cabo Verde. I Série, No17. Decreto-Lei no. 17/2014 de 10 de Março de 2014 do Ministério do Desenvolvimento Rural.

Burnett WJ, Benzie JAH, Beardmore JA, Ryland JS (1995) Patterns of genetic subdivision in populations of a clonal cnidarian, Zoanthus coppingeri, from the Great Barrier Reef. Mar Biol 122(4):665-673

Cruz I, Kikuchi RK, Longo LL, Creed JC (2015) Evidence of a phase shift to Epizoanthus gabrieli Carlgreen, 1951 (Order Zoanthidea) and loss of coral cover on reefs in the Southwest Atlantic. Mar Ecol 36: 318-325

Folmer O, Black M, Hoeh W, Lutz R, Vrijenhoek R (1994) DNA primers for amplification of mitochondrial cytochrome c oxidase subunit I from diverse metazoan invertebrates. Mol Mar Biol Biotechnol 3: 294-299

Irei Y, Nozawa Y, Reimer JD (2011) Distribution patterns of five zoanthid species in Okinawa Island. Japan. Zool Stud 50: 426-433

Karlson RH (1980) Alternative competitive strategies in a periodically disturbed habitat. Bull Mar Sci 30: 894-900

Karlson RH (1981) Reproductive patterns in Zoanthus sp. from Discovery Bay, Jamaica. Proc. $4^{\text {th }}$ Int. Coral Reef Symp 2: 699-704

Karlson RH(1988) Growth and survivorship of clonal fragments in Zoanthus solanderi Lesueur. J Exp Mar Biol Ecol 123(1): 31-39 
Morri CR, Cattaeno-Vietti R, Sartori G, Bianchi CN (2000) Shallow epibenthic communities of Ilha do Sal (Cape Verde Archipelago, eastern Atlantic). Arquipel Life Mar Sci Suppl 2: 157-165

Moses CS, Swart PK, Heimle KP, Dodge RE, Merino SE (2003) Pavements of Siderastrea radians on Cape Verde reefs. Coral Reefs 22: 506

Nunes FLD, Norris RD, Knowlton N (2011) Long distance dispersal and connectivity in amphi-Atlantic corals at regional and basin scales. PLoS ONE doi:10.1371/journal.pone.0022298

Ong CW, Reimer JD, Todd PA (2013) Morphologically plastic responses to shading in the zoanthids Zoanthus sansibaricus and Palythoa tuberculosa. Mar Biol 160: 1053-1064

Pax F (1910) Studien an westindischen Actinien. Zool Jahrb Supplement 11: 157-330

Pax F, Müller I (1956) Zoantharien aus Französisch Westafrika. Bulletin de l'Institut Fondamental de l'Afrique Noire 18:418-458

Reimer JD, Ono S, Fujiwara Y, Takishita K, Tsukahara J (2004) Reconsidering Zoanthus spp. diversity: molecular evidence of conspecifity within four previously presumed species. Zool Sci 21: $517-525$

Reimer JD, Hirose M, Wirtz P (2010) Zoanthids of the Cape Verde Islands and their symbionts: previously unexamined diversity in the Northeastern Atlantic. Contrib Zool 79: 147-163

Reimer JD, Foord C, Irei Y (2012) Species diversity of shallow water zoanthids (Cnidaria: Anthozoa: Hexacorallia) in Florida. J Mar Biol. doi:10.1155/2012/856079

Ryland JS, Lancaster JE (2003) Revision of methods for separating species of Protopalythoa (Hexacorallia: Zoanthidea) in the tropical West Pacific. Invertebr Syst 17: 407-428

Sebens KP (1977) Autotrophic and heterotrophic nutrition of coral reefs zoanthids. Proc. $3^{\text {rd }}$ Int. Coral Reef Symp 1: 397-404.

Sebens KP (1982) Intertidal distribution of zoanthids on the Caribbean coast of Panama: effects of predation and desiccation. Bull Mar Sci 32: 316-335 
Swain TD (2009) Phylogeny-based species delimitations and the evolution of host associations in symbiotic zoanthids (Anthozoa, Zoanthidea) of the wider Caribbean region. Zool J Linn Soc Lond 156: 223-238

Van der Land J (1993) Marine biota of the Cape Verde Islands. Courier Forschungsinstitut Senckenberg 159: 39-44

Wee HB, Reimer JD, Safuan M, Saidin J, Tan CH, Bachok Z (2017) Zoantharian abundance in coral reef benthic communities at Terengganu Islands, Malaysia. Reg Stud Mar Sci 12: 58-63 


\section{FIGURE LEGENDS}

Fig. 1: Location of the Cabo Verde Archipelago in the eastern Atlantic Ocean and the large aggregation (4 hectares) of Zoanthus spp. in Porto Cais Bay, Maio Island with nearby surveyed bays (black triangular arrows). The study area 'Zoanthus zone' is indicated by white area near the shoreline within the orthophotograph (40 cm/pixel; 2010 - UCCP MAHOT www.sit.gov.cv).

Fig. 2: Underwater picture of Zoanthus sociatus and Z. solanderi observed inside the 'Zoanthus zone' reported at Porto Cais Bay, Maio Islands (Cabo Verde, see Fig. 1). 